\title{
INFORMAÇÕES GEOCIENTÍFICAS: uma contribuição para o desenvolvimento sócio-econômico
}

\author{
Sonja Henie \\ Marilucia Ribeiro Pinheiro \\ Claudia Lopes
}

Resumo

Durante muito tempo a preocupação básica do CPRM - Serviço Geológico do Brasil foi a coleta e o armazenamento dos dados. Agora chegou a era da disseminação das informações. É tempo de tornar disponível tudo o que foi acumulado. Mostra como foi a realização deste processo de socialização das informações, através da DIDOTE - Divisão de Documentação Técnica, com o objetivo de alcançar a comunidade. Ressalta a importância e os fundamentos da natureza para a manutenção da qualidade de vida da sociedade.

Palavras chave

Socialização da Informação: Informações geocientíficas; Geologia Social; Serviço Geológico do Brasil

Criada pelo Decreto 764 de 15 de agosto de 1969, a CPRM - Companhia de Pesquisa de Recursos Minerais, inicialmente, tinha como objetivo estimular o descobrimento e intensificar o aproveitamento dos recursos minerais e hídricos do Brasil, apoiando tecnicamente os órgãos da administração direta do Ministério das Minas e
Energia, incentivando e cooperando com a iniciativa privada em todas as suas áreas de atuação, desde que essa contratação envolvesse o nível de especialização da empresa e caracterizasse uma atividade suplementar à atuação da iniciativa privada.

São três as fases principais da CPRM em seus 28 anos de existência: 
- Década de 70 - com recursos financeiros e materiais suficientes, além de amplo quadro técnico, executou o levantamento geológico de quase metade do território brasileiro, em escala 1:250.000, descobrindo depósitos minerais importantes;

- Década de 80 - quando recursos financeiros se tornaram excassos, os trabaIhos de levantamentos geológicos básicos do país foram praticamente paralisados.

- Década de 90 - consolidação da empresa como um centro de distribuição de informações básicas, resultando no comprometimento de sua missão "Garantir as informações geológicas e hídricas fundamentais ao desenvolvimento econômico e social do País".

O Brasil vivencia uma nova realidade nos setores minerais e hídricos . Criou-se um ambiente propício para a dinamização das atividades minerárias com a emenda constitucional (EC 6, de 15/08/95) que derrubou as restrições ao capital externo na mineração e quebrou o monopólio do governo na área do petróleo, juntamente com a política de abertura para o comércio exterior $e$ a desestatização. A essas medidas veio se somar a reformulação ao Código de Mineração, que reduziu a burocracia junto ao DNPM - Departamento Nacional da Produção Mineral, estimulando a pesquisa e a mineração, aquecendo e movimentando ainda mais o setor mineral brasileiro.

A criação da Agência Nacional de Energia Elétrica - ANEEL, em substituição ao DNAEE, e o estabelecimento da Política Nacional de Recursos Hídricos, contribuíram para as atividades da CPRM, referentes à pesquisa de águas superficiais $e$ subterrâneas
A CPRM, sensível a esta nova realidade, procurou acelerar sua adaptação interna e externa, em seqüência ao seu Plano de Reestruturação iniciado em 1991, transformando-se assim, em um organismo específico destinado a promover o conhecimento geocientífico do país, não só para a procura de respostas aos problemas da constituição terrestre, mas, para a partir da solução destes, encontrar aplicações práticas e comerciais de interesse e uso do homem. Foi o início dos planos anuais de trabalho e planejamento a longo prazo, resultando em projetos, tais como o Programa GATE - Informações Básicas para a Gestão Territorial, enfatizando a questão ambiental e os Levantamentos Hídricos.

Coroando a boa fase, a CPRM foi transformada em Empresa Pública, tornando realidade o Serviço Geológico do Brasil (Lei 8.970, de 28/12/94), cujo novo Estatuto Social foi publicado no Diário Oficial da União (Decreto 1.524, de 20/06/95).

O Serviço Geológico não só transferiu tecnologia (principalmente aos países da América Latina e África), como também recebeu, por intermédio de treinamento ou aperfeiçoamento de seu corpo técnico, através de assessorias e consultorias de especialistas internacionais. As ações anteriores são um reflexo à política de divulgação, prestação de serviços e cooperação técnica, em consonância com as diretrizes do Ministério de Relações Exteriores e de Ministério de Minas e Energia, tendo em vista o estreitamento e o fortalecimento das relações bilaterais entre a CPRM e entidades congêneres de outros países.

Com a participação de todos os representantes oficiais dos países integrantes do Mercosul, constituiu-se em 1996, a Comissão Temática em Geologia e Recursos Minerais, com os seguintes objetivos: 
1. elaborar a gestão territorial para atender as demandas da sociedade referente às Geociências;

2. integrar num sistema de informação geográfica à informação geológica de base e cartas temáticas associadas, que compreenda a totalidade dos países integrantes;

3. georeferenciar e digitalizar dados para prover a confecção do mapa de integração;

4. criar um banco de dados geológicos com acesso via Internet.

Consciente do valor da informação para o desenvolvimento do país, a CPRM mantém no Escritório Rio de Janeiro, a Divisão de Documentação Técnica - DIDOTE, o Núcleo de Informação em Economia Mineral, além de centros de informação, uma em cada Unidade Regional (Belém, Belo Horizonte, Fortaleza, Goiânia, Manaus, Porto Alegre, Porto Velho, Recife, Salvador, São Paulo e Teresina).

Concentrando significativo acervo de dados e informações geocientíficas, a DIDOTE atua como depositária da produção técnico científica da empresa, administrando suas coleções (convencional e fotocartográfica), processando e disseminando a informação técnica e em especial, promovendo estreita articulação com o corpo técnico, no fornecimento do suporte informacional, necessário ao desempenho de suas atividades. Oferecendo assim, os seguintes serviços e produtos:

1. Alimentação e geração de bases de dados

2. Serviços de alerta (Sumários de Periódicos e Novas Aquisições)
3. Serviços de alerta " on line" (Sumário Eletrônico, Sumários de Periódicos e Novas Aquisições)

4. Comutação bibliográfica nacional (COMUT) e internacional (BLDSC)

5. Empréstimo local e interbibliotecário

6. Fornecimento de documentação fotocartográfica

7. GEODESC - Vocabulário Controlado para Geociências

8. Normalização de trabalhos técnicos

9. Catalogação na fonte de publicações da Empresa

10. Programa de distribuição, doação e permuta de publicações

11. Programa de venda de publicações

12. Intranet

13. SEUS - Serviço de Atendimento aos Usuários

14. Guia de Instituições Geocientíficas

A DIDOTE atua também como Biblioteca base do COMUT e como Centro Distribuidor de Informação em Geociências na Rede Antares, coordenada pelo Instituto Brasileiro de Informação em Ciência e Tecnologia - IBICT. A Rede Antares ocorre no âmbito do Sub-Programa de Informação em Ciência e Tecnologia do Programa de Apoio ao Desenvolvimento Científico e Tecnológico (PADCT/ICT). 
O atendimento ao cliente na "Era da Informação" está constituindo-se no principal fator de vantagem competitiva entre as organizações. É fundamental para os casos de sucesso a adoção de uma atitude pró-ativa. Indo ao encontro do cliente e não esperando que ele venha até o fornecedor. Significa a criação de uma atenção especial e total aos clientes e a busca permanente de inovação em todas as áreas de serviço.

Mediante um padrão de atendimento qualificado, estrutura de equipe, coleções e equipamentos, a DIDOTE posiciona-se como interface entre a empresa e a comunidade, através do SEUS - Serviço de Atendimento aos Usuários, que vem confirmar e reiterar a sua missão, privilegiando a democratização e a qualidade dos dados e das informações geocientíficas.

Criado para facilitar o acesso às $\mathrm{Ba}$ ses de Dados institucionais e possibilitar independência de qualquer tipo de ligação via teleprocessamento, a CPRM lançou em 1994, no Congresso de Geologia, a primeira versão do Micro Siga (Sistema de Informações Geológicas do Brasil) em CD-Rom, que atualmente encontra-se disponível não só nas universidades, como também, nas empresas de mineração, instituições de pesquisas e órgãos governamentais do Brasil e do exterior. Sua interface gráfica passará a denominar-se MicroSIR (Sistema de Informações em Recursos Hídricos), arrolando maior número de bases de dados.

Em 1996, a CPRM tornou disponível sua "home page" (http://www.cprm.gov.br), oferecendo acesso a um conjunto de cerca de 200.000 registros contidos nas Bases de Dados Bibliográficas e Georreferenciadas, relacionadas a seguir:

Água - Água Subterrânea (atualiza- ção set./97)

\section{Bibl - Acervo Bibliográfico da CPRM (atualização mar./98)}

Meta - Ocorrências Minerais (atualização mar./98)

Proj - Acervo de projetos executados pela CPRM (atualização mar./98)

A quantidade de solicitações de informações tem sido significativa, constante e diversificada, registrando o total de 16.723 visitantes (27/03/98). A informação está sendo disseminada com qualidade e em tempo real, não só em nível nacional, como internacional.

Paralelo à "home page", foi elaborada a Intranet com o objetivo de diluir não só as barreiras entre os indivíduos, mas também, as barreiras físicas e geográficas entre eles.

Participando ativamente, a DIDOTE, através de seu próprio "site", supre o seu corpo técnico com as mais recentes aquisições, links interessantes e importantes dicas para um bom desempenho no Programa de Qualidade que a Empresa está implantando. Em 1996, preocupada não só com a qualidade de vida dos empregados, como também com a qualidade dos produtos oferecidos, foi iniciado o Programa Qualidade CPRM, em parceria com a Fundação Christiano Ottoni.

Nesta oportunidade, a DIDOTE avalia seus programas, metas e objetivos, resultando no "Repensando a Biblioteca", definindo sua missão como sendo: "Incentivar e facilitar a utilização do acervo, além de tornar disponíveis dados e informações geocientíficas para a comunidade", e sua visão de futuro como sendo: "Transformar a CPRM em um centro de excelência no 
país, na transferência de dados e informações geocientíficas".

Durante os Congressos de Geologia, a atuação do SEUS (seus@cristal.cprm.gov.br), em parceria com a área de Marketing e demais representantes das linhas de serviço da Empresa, torna-se evidenciada pelo valioso contato e necessário "feedback" dos participantes. Cabe ressaltar que a partir desse momento são geradas inúmeras parcerias, ampliando o leque da comunidade de clientes.

Realizado pelo SEUS, o atendimento pós-congresso, oferece publicações ou documentação fotocartográfica de interesse, não só implementando novos contatos, mas principalmente, gerando credibilidade para a Empresa, além de manter crescente e diversificado o universo de clientes do Serviço Geológico do Brasil.

As ações acima demonstram a capacidade da CPRM em se adaptar a um novo tempo em que as expectativas se voltam para as áreas econômica, social e de meio ambiente. Sua missão deixa de ser simplesmente técnica, passando a ser uma provedora de informações em geociências voltando-se para atender às demandas por produtos e serviços multidisciplinares de interesse da comunidade maior: a Sociedade Brasileira.

\section{REFERÊNCIAS}

BERBERT, Carlos Oiti. Serviço Geológicos Nacionais: o quê são e o quê fazem. Brasil Mineral, v.11, n.120, p.32-35, ago./94.

A geologia como base de planejamento sócio-econômico. In: FORUM NACIONAL SOBRE GEOLOGIA DE MEIOS URBANOS, 1., 1993, Porto Alegre.
Anais... Porto Alegre: Associação Profissional Sul-Brasileira de Geólogos: Assembléia Legislativa do Estado do Rio Grande do Sul: UFRS, 1993. 152p., p.2-3.

. Geologia social: a nova visão dos Serviços Geológicos. A Terra em Revista, v.1, n.0, p.9-10, ago./95.

Hablan los Servicios Geologicos. GEOMINER, n.1, p.4, maio/96.

- O Serviço Geológico do Brasil a sua disposição. Fator GIS, v.3, n.11, p.79, out./dez. 1995.

CPRM. Serviço Geológico do Brasil. CPRM 96: síntese de realizações. Rio de Janeiro, 1997. 26p.

. Mercosul: I Reunião Técnica da Comissão Temática Geologia e Recursos Minerais. Porto Alegre, 1996. 1v.

DIDOTE. Divisão de Documentação Técnica. DIDOTE: atividades, produtos e serviços. Rio de Janeiro, 1996. 1v. n.p.

FREIRE, Tania. Mecanismos de recuperação de informação em geociências. In: CONGRESSO BRASILERIO DE GEOLOGIA, 38., 1994, Camboriú. Boletim de resumos expandidos. Camboriú: SBG: DNPM: CPRM, 1994. 3v., v.2, p.350-352.

- O atendimento ao cliente no Serviço Geológico do Brasil. In: CONGRESSO BRASILEIRO DE BIBLIOTECONOMIA, 18., 1997, São Luis. Anais ... São Luis: Associação Profissional dos Bibliotecários do Estado do Maranhão, 1997. 5v., v.5, p.1-6. 


\section{Sonja Henie}

Analista de Informação - CPRM - Serviço Geológico do Brasil

shenie@cristal.cprm.gov.br

\section{Marilucia Ribeiro Pinheiro}

Analista de Informação - CPRM - Serviço Geológico do Brasil

mlucia@cristal.cprm.gov.br

\section{Claudia Lopes}

Analista de Informação - CPRM - Serviço Geológico do Brasil clopes@cristal.cprm.gov.br

\section{Title}

Geo-scientific informations: a contribution for the social-economical development

\begin{abstract}
The main concern of the Brazilian Geological Service (CPRM) was, for a long time, the data gathering and storage of geological information. Now it is time for disseminating these informationthrough DIDOTE (Division of Tchnical Documentation) enphasizing its importance in the contribution for the quality of life in our society.
\end{abstract}

\section{Keywords}

Socialization of Information; Geo-scientific Informations; Social Geology; Brazilian Geological Service

\section{Titulo}

Informaciones geocientificas: una contribución para el desarrollo socio económico

\section{Resumen}

Hace mucho tiempo que la preocupación básica del CPRM - Servicio Geológico de Brasil fue la recolección y almacenamiento de los datos. Ahora, llegó la era de la diseminación de las informaciones. Es tiempo de tornar disponible todo lo que fue acumulado. Muestra como fue la realización de este proceso de socialización de las informaciones, a través de la DIDOTE - División de Documentación Técnica, con el objetivo de alcanzar a la comunidad. Resalta la importancia y los fundamentos de la naturaleza para la manutención de la cualidad de vida de la sociedad.

\section{Palabras-Clave}

Socialización de la Información; Informaciones Geocientíficas; Geología Social; Servicio Geológico de Brasil

Artigo recebido em: 30/04/98 